\title{
A problemática da planta genérica de valores no IPTU de um município gaúcho
}

Silvia Maria Parmeggiani Gering

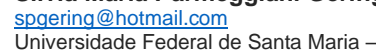
UFSM, Santa Maria, Rio Grande do Sul, Brasil

Nelson Guilherme Machado Pinto nelguimachado@hotmail.com Universidade Federal de Santa Maria UFSM, Santa Maria, Rio Grande do Sul, Brasil

\section{Kelmara Mendes Vieira}

kelmara@terra.com.br UFSM, Santa Maria, Rio Grande do Sul, Brasil

\begin{abstract}
RESUMO
Os municípios devem promover a arrecadação dos tributos de sua competência para a realização das suas múltiplas atividades visando o bem comum dos cidadãos. No Município de Santa Maria (RS), o Imposto Sobre Propriedade Predial e Territorial Urbana - IPTU destaca-se pelo baixo nível de arrecadação, influenciado, em parte, pela defasagem da planta genérica de valores (PGV). O estudo teve como objetivo constatar e identificar os percentuais da defasagem da planta genérica de valores. Então, utilizou-se uma pesquisa descritiva, com abordagem quantitativa e técnicas estatísticas descritivas. Serviram de amostra os dados cadastrais e financeiros de 126.190 imóveis registrados no setor imobiliário. Com base na estatística descritiva, constatou-se que os valores venais e tributáveis estão abaixo do valor de mercado, devido a aplicação de redutores e defasagem da planta genérica de valores. O desequilíbrio estimado entre os valores praticados pelo mercado e pela prefeitura através da PGV, apresentam uma defasagem média de $461,29 \%$ e $1.575,53 \%$, respectivamente para os valores venais e valores tributáveis dos imóveis. A desatualização de ambos é perceptível em toda cidade, demonstrando a necessidade de uma revisão dos valores que compõem a base de cálculo do IPTU.
\end{abstract}

PALAVRAS-CHAVE: Município, Receita, IPTU, Planta Genérica de Valores. 


\section{INTRODUÇÃO}

A União, os estados e os municípios necessitam de recursos para a realização das múltiplas atividades, bem como para propiciar serviços básicos que proporcionem qualidade de vida aos seus habitantes. Os municípios obtêm esses recursos através da cobrança de impostos, taxas e transferências correntes dos outros entes da Federação. Os impostos municipais, de acordo com o Art. 156 da CF/88 (BRASIL, 1988), são: o Imposto Sobre a Propriedade Predial e Territorial Urbana - IPTU; o Imposto sobre a Transmissão Inter Vivos de Bens Imóveis - ITBI, e o Imposto Sobre Serviços de Qualquer Natureza - ISS.

Quanto ao IPTU, embora o Brasil tenha uma das maiores cargas tributárias mundiais, não se observa uma carga no mesmo nível para esse imposto; além disso, a arrecadação é heterogênea, pois varia muito de um município para outro (AFONSO; ARAÚJO; NÓBREGA, 2013). Apesar das diferenças de arrecadação em cada cidade, estado ou região, o IPTU constitui-se numa importante fonte de financiamento, e as causas que afetam a sua arrecadação são semelhantes nos vários municípios.

Uma das causas é a negligência por parte da administração pública quando se refere a arrecadação desse imposto, principalmente pelo fato de haver defasagem da planta genérica de valores, cadastro desatualizado, carência de pessoal qualificado e falta de investimento para criar processos mais eficientes para a administração e controle da arrecadação do IPTU (CUPERTINO, 2013). No município de Santa Maria, os balancetes contábeis demonstram que a receita do IPTU se encontra praticamente estagnada, não refletindo o acréscimo referente ao número de imóveis construídos na cidade.

Destaca-se que o IPTU é um imposto pago pelos donos de apartamentos, casas, prédios e terrenos, e assim, identifica-se que existem problemas no crescimento da arrecadação ao confrontá-lo com o aumento do número de imóveis na cidade. Tal afirmação é legitimada através dos dados do IBGE, apresentados pela Agência de Desenvolvimento de Santa Maria (ADESM, 2017), que informam que a cidade de Santa Maria demonstrou um crescimento de $19 \%$ em relação ao seu número total de domicílios (local estruturalmente separado e independente que se destina a servir de habitação a uma ou mais pessoas) do ano de 2000 para 2010. Por outro lado, através de uma série histórica de dados extraídos dos balancetes de arrecadação, para os exercícios de 2004 até 2016, cujos valores foram transformados em Unidades Fiscais Municipais (UFM), verificase o IPTU obteve um crescimento médio de apenas de 3,98\%.

Outro dado que demonstra a deficiência na arrecadação do IPTU em Santa Maria (RS) é a arrecadação média per capita do município em relação à média per capita da Região Sul. De acordo com dados da plataforma de inteligência DEEPASK (2014), a arrecadação média de IPTU, no ano de 2014, para municípios de 100 até 500 mil habitantes da Região Sul, situava-se em torno de R\$124,28 por habitante, enquanto que em Santa Maria (RS), neste mesmo ano, a média encontrava-se em torno de $\mathrm{R} \$ 96,03$ por habitante.

A partir disso, identifica-se que a deficiência na arrecadação da receita do IPTU é oriunda de, no mínimo, três problemas: necessidade de realização de recadastramento para identificar as áreas construídas, que não estão registradas no cadastro imobiliário; primordialidade de revisão e atualização na planta de 
valores do município, para mapear as áreas que estão valorizadas e contribuem aquém do valor real dos imóveis; e a inadimplência, referente aqueles valores lançados e não pagos.

Dada essa contextualização a respeito da arrecadação, tem-se como objetivo constatar e identificar os percentuais da defasagem da planta genérica de valores no Município de Santa Maria (RS) para conscientizar da importância de sua atualização. Destaca-se que a organização política administrativa é estabelecida na CF/88 (BRASIL, 1988), a qual também define o funcionamento do Sistema Tributário Nacional, instituindo competências tributárias de cada ente federado, pois estes necessitam de recursos para manter a máquina administrativa e disponibilizar serviços para o bem comum. Em vista disso, as administrações municipais devem trabalhar em prol de eficientização de seus processos de arrecadação na aplicação da receita própria, sem instituir aumento da carga tributária.

Assim, a relevância do estudo é constituir-se em instrumento de demonstração da defasagem da planta genérica de valores no município, de modo a contribuir para a elaboração de estratégias e planos de alteração da mesma, baseadas em dados reais, com maior poder de convencimento para a população e seus representantes. Do mesmo modo, a relevância teórica deste trabalho está em contribuir para os estudos da gestão pública, especificadamente na área da tributação municipal. Além dessa introdução, o artigo está estrutura nos seguintes capítulos: referencial teórico, IPTU em Santa Maria, método, análise dos resultados e considerações finais.

\section{REFERENCIAL TEÓRICO}

O Art. 145 da CF/88 (BRASIL, 1988) estabelece que as receitas tributárias próprias nos municípios são compostas de impostos, taxas e contribuição de melhoria. Os impostos têm como características serem instituídos mediante previsão legal, sem vinculação, e sua imposição independe de qualquer atuação estatal específica em favor do contribuinte (AMARO, 2016).

Assim, mediante competência atribuída pela $\mathrm{CF} / 88$, os municípios têm o produto da arrecadação de seus tributos, denominada receita própria, integralmente para si. Para tanto devem editar legislação específica e cobrá-los no âmbito dos respectivos territórios. Além disso, cada município deve organizar seu sistema de arrecadação em código tributário próprio, respeitadas as regras do Código Tributário Nacional (AFONSO; ARAÚJO; NÓBREGA; 2013).

As receitas próprias, conforme enfatizado por Soares, Flores e Coronel (2014), se apresentam como uma importante fonte de recursos para a instituição de melhorias nos municípios. Apesar disso, de acordo o "Índice FIRJAN de Gestão Fiscal - Receita Própria" - IFGF Receita Própria (FIRJAN, 2017), em 2016, 81,70\% das cidades brasileiras ficaram com conceito $D$, ou seja, 3.714 cidades não geraram sequer $20,00 \%$ de suas receitas nesse ano, e apenas 136 municípios em todo o país obtiveram conceito A, por terem arrecadado com tributos municipais mais de $40 \%$ de suas receitas. Esse índice demonstra um significativo desequilíbrio entre o volume de receitas e a arrecadação própria na grande maioria das prefeituras brasileiras. Diante da conjuntura apresentada pela composição das receitas 
municipais no país, é relevante que se desenvolvam ações consistentes focadas no fortalecimento das receitas próprias.

Por sua vez, o Imposto Predial e Territorial Urbano (IPTU) é um tributo imobiliário, tipicamente local, que onera os proprietários de imóveis localizados na área urbana do município. O IPTU está estabelecido no inciso I do Art. 156 da CF/88 (BRASIL, 1988) e nos Arts. 32 a 34 do da Lei no 5.172, de 25 de outubro de 1966, que estabelece o Código Tributário Nacional - CTN (BRASIL, 1966), e tem como sujeito passivo o proprietário do imóvel, o titular do seu domínio útil, ou o seu possuidor a qualquer título.

Conforme Afonso, Araújo e Nóbrega (2013, p. 63), a CF/88 acertou ao determinar que o IPTU deve ser de competência municipal, considerando a "inamovibilidade da base imponível", pois os imóveis não podem migrar de um município para outro. Além disso, a proximidade entre o contribuinte e o poder público, o qual tem por dever ser provedor de serviços à população, reforça o argumento de que esse imposto deve ser de jurisdição local.

A base de cálculo do IPTU, como estabelecido no Art. 33 do CTN (BRASIL, 1966), será o valor venal do imóvel (terreno mais construção), desconsiderando os valores advindos de bens móveis mantidos em caráter permanente ou temporário. Para a determinação dessa base, o administrador municipal estima o preço provável do imóvel, tendo em vista atributos registrados no cadastro imobiliário da prefeitura, sendo que o tipo, o padrão construtivo e a localização influenciam no valor da construção. Logo, pode-se considerar que o valor venal do imóvel é o valor de mercado presumido pela administração municipal (AFONSO, ARAÚJO, NÓBREGA, 2013; SÁ, et al., 2013; CARVALHO JR., 2011).

De acordo com Carvalho Jr. (2011), não existe legislação federal que determine como estabelecer o valor venal. Assim, cabe a lei ordinária municipal defini-lo, dispondo os critérios e parâmetros a serem adotados para a avaliação. $O$ conjunto de presunções relativas aos critérios e parâmetros que fundamentam o valor venal denomina-se planta genérica de valores - PGV. Para Sá, et al. (2013), a PGV determina o valor por metro quadrado para cada região ou via pública, e através dela consegue-se determinar um valor de terreno aproximado ao real em cada logradouro, por um período de tempo, já que o mercado imobiliário é dinâmico.

Diante disso, ressalta-se a importância da atualização da planta genérica de valores, pois é sobre o valor determinado por essa que incidirá a alíquota do imposto, influenciando na arrecadação e no tratamento isonômico entre os contribuintes. Nesse sentido, Oliveira Jr. (2014) enfoca que até nas prefeituras melhores qualificadas a gestão do IPTU possui entraves legais de afetam o potencial de arrecadação. Demonstra-se que a necessidade de aprovação pelo legislativo das alterações da base de cálculo da PGV constitui-se num dos maiores obstáculos. Todavia, os municípios devem promover ajustes nas legislações, assegurando que os valores venais sejam determinados por critérios técnicos.

\section{O IPTU EM SANTA MARIA (RS)}

No Município de Santa Maria, nos Arts. 3o a 21 da Lei Complementar Municipal 2001), estão disciplinados a forma de incidência, o sujeito passivo, a base de 
cálculo e alíquotas, a inscrição e o lançamento do IPTU. Em relação a matriz tributária destaca-se que a planta genérica de valores, instrumento que define os diferentes valores dos terrenos e edificações do município, teve a sua última atualização no ano de 1995, através da Lei Municipal no 3933, de 21 de dezembro de 1995 (SANTA MARIA, 1995). Posteriormente, conforme determina o Art. 241 da LCM n 02/2001 (SANTA MARIA, 2001) está somente foi reajustada anualmente pelo Índice Nacional de Preços ao Consumidor Amplo (IPCA), através da variação da unidade fiscal municipal (UFM) que é a unidade padrão indexadora dos tributos municipais.

O Decreto Executivo Municipal $n^{\circ} 145$, de 04 de dezembro de 2008 (SANTA MARIA, 2008), regulamenta o IPTU em Santa Maria, definindo o que é prédio, unidade predial, terreno e gleba. Ainda, identifica quais são os tipos de terrenos, ou seja, terreno interno, terreno encravado, terreno de esquina, terreno com duas ou mais frentes e terreno em construção. Estabelece, além disso, a forma de cálculo do IPTU e as tipologias construtivas, bem como a determinação dos redutores.

O Art. 142 do CTN (BRASIL, 1966) estabelece que o lançamento, cujo ato é vinculado e obrigatório, visa determinar a matéria tributável, calcular o montante do tributo devido e identificar o sujeito passivo. Salienta-se que lançamento de ofício é aquele realizado pela administração tributária de maneira direta ou revisional, com base nos respectivos cadastros, cabendo ao contribuinte contestar o seu valor (CHIMENTI, PIERRI, 2012). Assim, o IPTU é lançado anualmente, de ofício pela prefeitura, através de sistema informatizado, de acordo com o Art. 18 da Lei Complementar Municipal n 02, de 28 de dezembro de 2001 (SANTA MARIA, 2001), com base no cadastro imobiliário existente.

Assim, analisando-se a arrecadação dos impostos municipais, observa-se que o ISS e o ITBI obtiveram, respectivamente, um crescimento médio anual real de $7,47 \%$ e $10,00 \%$ no período. O IPTU, por sua vez, atingiu o índice de 3,98\%, encontrando-se estagnado quando comparado ao crescente número de imóveis construídos no período.

A variação na performance das receitas próprias tem motivos específicos para cada imposto. A experiência mostra que uma série de fatores conjuntamente com o aperfeiçoamento da legislação colaboraram para o aumento significativo da arrecadação do ISS. Quanto à receita do ITBI, seu desempenho está relacionado ao aumento das transações imobiliárias na cidade; convênio firmado com o Cartório de Registro de Imóveis, vinculando o registro à apresentação da guia de recolhimento do tributo; e a ampliação de investimentos, mediante planos governamentais, como o Plano de Aceleração do Desenvolvimento em Crescimento - PAC (SOARES, FLORES, CORONEL, 2014).

Em relação ao IPTU, a arrecadação foi impactada pelos reajustes abaixo do índice UFM; e descontos e benefícios fiscais, visando a sua arrecadação antecipada (SOARES, FLORES, CORONEL, 2014). Ainda, sobre a arrecadação do IPTU, acrescenta-se outros três problemas: a necessidade de revisão da Planta de Genérica de Valores e a realização de recadastramento imobiliário, bem como a realização de ações para o combate da inadimplência. Em notícias veiculadas na imprensa local, verifica-se que a Prefeitura de Santa Maria está promovendo o estudo para uma nova planta genérica de valores e está em andamento o recadastramento da zona urbana do município (DIÁRIO DE SANTA MARIA, 2017a). 
A planta genérica de valores influencia diretamente os valores lançados anualmente, pois determina os diferentes valores dos terrenos e edificações do município. Destaca-se que de 1995, ano da PGV, até os dias de hoje, no município, houve um intenso crescimento por consequência do aquecimento imobiliário, com novos loteamentos e a valorização das áreas já urbanizadas, inclusive com o surgimento de vários condomínios de luxo. Tal fato fez com que houvesse, cada vez mais, um distanciamento entre o valor real do imóvel e o valor tributado sobre ele. Assim, uma atualização da planta genérica de valores proporcionaria uma adequação das receitas próprias do município frente à valorização das propriedades.

Decorrente dessas necessidades, a administração municipal, através do Edital no 02/2013, na Modalidade de Concorrência, contratou empresa especializada na área, para realização de elaboração de proposta de nova planta genérica de valores e realização de recadastramento imobiliário, através do Processo Licitatório no 342/2013. Quanto à PGV, o Termo de Referência estabelece que a contratada deveria elaborar proposta de planta genérica de valores, objetivando a definição de novos valores unitários fiscais dos imóveis que formarão a base de cálculo dos tributos.

Constata-se correto o procedimento da administração municipal pois, para Carvalho Jr. (2017), é recomendável que os municípios possam terceirizar a atividade de avaliação imobiliária para elaboração da planta genérica de valores, tendo em vista que a presunção do valor venal do imóvel quando realizada em massa é tarefa muito complexa. Recomenda ainda, para tal, a realização de convênios e consórcios intermunicipais. Além disso, à modernização tecnológica tem proporcionado, nos municípios maiores, o recadastramento físico através de georreferenciamento e fotos aéreas. Essa técnica permite captar loteamentos e mudanças no uso e na área construída dos imóveis.

Em tempo, salienta-se que de acordo com notícias veiculadas na imprensa local o projeto da nova planta de valores estaria concluído pela equipe técnica, contudo se enviado no exercício de 2018 para a Câmara de Vereadores, atualizaria os valores do IPTU para o exercício de 2019, caso aprovada (DIÁRIO DE SANTA MARIA, 2017b). Neste quesito, é necessário o convencimento dos representantes eleitos pelo povo, para que a aprovação da mesma seja vista tecnicamente como uma correção das distorções no valor da tributação e não simplesmente como aumento de impostos.

\section{MÉTODO DE PESQUISA}

Destaca-se que esta pesquisa utilizou o método de abordagem dedutivo e quanto à natureza considerou-se como aplicada. Além disso, utilizou-se, como forma de abordagem ao objetivo do estudo, o método de pesquisa quantitativo, pois está relacionado à quantificação de dados e baseada em técnicas estatísticas para seu tratamento. Do ponto de vista dos objetivos, esta pesquisa enquadrou-se como descritiva, e quanto aos procedimentos metodológicos, realizou-se uma pesquisa bibliográfica para a fundamentação teórica; documental, com a análise da legislação e documentos pertinentes para a identificação dos bairros e zonas fiscais; convergindo para um estudo de caso, o qual representa uma maneira consistente de realizar análise de dados (MICHEL, 2015; MATIAS-PEREIRA, 2016). 
O cenário de estudo são os imóveis do Município de Santa Maria, localizado no Estado do Rio Grande do Sul, Brasil. O município constitui-se em importante centro regional, e devido as suas características possui uma forte expansão imobiliária, acompanhada da valorização dos imóveis, o que deveria impactar diretamente na arrecadação do IPTU. Por isso a população alvo do estudo concentra-se nas 156.153 economias, prediais ou territoriais, registradas no cadastro imobiliário do município.

Os dados foram obtidos com base na Lei no 12.527 , de 18 de novembro de 2011 (BRASIL, 2011), que regulamenta o direito constitucional de acesso às informações públicas. Essa norma se aplica a todos os órgãos e entidades da administração pública, inclusive aos municípios, e cria mecanismos que possibilitam o recebimento de informações públicas dos órgãos e entidades, desde que observados os princípios legais.

De acordo Lakatos e Marconi (2017) os dados caracterizam-se como secundários, e foram extraídos do Sistema Informatizado de Administração de Receita através de pesquisa Structured Query Language - SQL, a qual é usada para estabelecer comunicação com o banco de dados, e posteriormente migrados para o software Excel. A revisão da extração foi efetuada através da comparação dos dados planilhados com as informações registradas nos relatórios cadastrais emitidos pelo Sistema Informatizado de Administração de Receita.

Para identificar quais os cadastros são os contribuintes do IPTU, realizou algumas exclusões. Assim, do total de cadastros (156.153) foram excluídos cadastros inativos (18.006), cadastros imunes (2.982), cadastros isentos (3.916), inconsistências cadastrais (459), cadastros sem lançamento (4.600). Disso, resultou uma amostra de 126.190 imóveis, contribuintes do IPTU do Município de Santa Maria (RS), com situação ativa, registrados na base de dados no dia 10/10/2017.

Destaca-se que os dados são inseridos no Sistema Informatizado de Administração de Receita de acordo com o que estabelece a Lei Complementar Municipal $\mathrm{n}$ 0 02, de 28 de dezembro de 2001 - Código Tributário Municipal (SANTA MARIA, 2001), a Lei Municipal no 3933, 21 de dezembro de 1995 - planta genérica de valores (SANTA MARIA, 1995), o Decreto Executivo Municipal no 145, de 04 de dezembro de 2008 - que regulamenta IPTU (SANTA MARIA, 2008). Esses dados dão origem as variáveis utilizadas na análise, as quais são apresentadas no Quadro 1.

Quadro 1 - Descrição das variáveis.

\begin{tabular}{|l|l|}
\hline \multicolumn{1}{|c|}{ Nome da variável } & \multicolumn{1}{c|}{ Descrição } \\
\hline $\begin{array}{l}\text { Zona fiscal e subzona } \\
\text { fiscal }\end{array}$ & $\begin{array}{l}\text { Determina a zona e subzona fiscal que o imóvel está enquadrado de } \\
\text { acordo com a Planta Genérica de Valores. Existem 5 (cinco) Zonas } \\
\text { Fiscais e 31 (trinta e uma) Subzonas Fiscais, as quais são localizadas em } \\
\text { elipses equidistantes do ponto central da cidade. }\end{array}$ \\
\hline Valor venal do terreno & $\begin{array}{l}\text { Demonstra o valor venal do terreno de acordo com a PGV e a área do } \\
\text { terreno ou sua fração ideal. }\end{array}$ \\
\hline $\begin{array}{l}\text { Valor venal da } \\
\text { construção }\end{array}$ & $\begin{array}{l}\text { Demonstra o valor venal da construção de acordo com a PGV e a área } \\
\text { construída. }\end{array}$ \\
\hline Valor venal do imóvel & $\begin{array}{l}\text { Demonstra o valor venal do imóvel. Obtido através da soma do valor } \\
\text { venal do terreno e do valor venal da construção. }\end{array}$ \\
\hline
\end{tabular}




\begin{tabular}{|l|l|}
\hline Valor tributável & $\begin{array}{l}\text { Demonstra o valor tributável do imóvel. Obtido através da aplicação } \\
\text { dos redutores sobre o valor venal do imóvel. }\end{array}$ \\
\hline Valor do imposto & $\begin{array}{l}\text { Demonstra o valor do imposto. Obtido através da aplicação da } \\
\text { respectiva alíquota sobre o valor tributável. }\end{array}$ \\
\hline $\begin{array}{l}\text { Valor do imposto com } \\
\text { adimplência }\end{array}$ & $\begin{array}{l}\text { Demonstra o valor do imposto após a incidência dos descontos de } \\
\text { adimplência. Obtido através da aplicação dos respectivos percentuais } \\
\text { de descontos de adimplência sobre o valor do imposto. }\end{array}$ \\
\hline $\begin{array}{l}\text { Valor da Taxa de Coleta } \\
\text { de Lixo - TCL }\end{array}$ & Demonstra o valor da Taxa de Coleta de Lixo. \\
\hline $\begin{array}{l}\text { Valor da Contribuição } \\
\text { de Iluminação Pública - } \\
\text { CIP }\end{array}$ & $\begin{array}{l}\text { Demonstra o valor da Contribuição de Iluminação Pública para os } \\
\text { terrenos baldios. }\end{array}$ \\
\hline Valor total do tributo & Demonstra o valor total do tributo (IPTU + TCL + CIP). \\
\hline Valor da parcela & $\begin{array}{l}\text { Demonstra o valor da parcela. Obtido através da divisão do total do } \\
\text { tributo pelo número de meses do ano, respeitado o valor mínimo de 5 } \\
\text { UFMs por parcela. }\end{array}$ \\
\hline $\begin{array}{l}\text { Percentual do valor } \\
\text { tributável sobre o valor } \\
\text { venal do imóvel }\end{array}$ & $\begin{array}{l}\text { Identifica o percentual do valor tributável sobre o valor venal do } \\
\text { imóvel. Obtido através da divisão do valor tributável pelo valor venal do } \\
\text { imóvel (P=VT/VV). }\end{array}$ \\
\hline Preço do m² venal & $\begin{array}{l}\text { Identifica o valor venal estimado do } \mathrm{m}^{2} \text { da área construída. Obtido } \\
\text { através da divisão do valor venal do imóvel pela área construída } \\
\text { (VVm²=VV/área). }\end{array}$ \\
\hline Preço do m² tributável & $\begin{array}{l}\text { Identifica o valor tributável estimado do m² da área construída. Obtido } \\
\text { através da divisão do valor tributável do imóvel pela área construída } \\
\text { (VTm²=VT/área). }\end{array}$ \\
\hline
\end{tabular}

Fonte: Elaborado pelos autores (2018).

Para o processamento dos dados foi utilizado o software IBM SPSS Statistics 20 , sendo a análise realizada com base na estatística descritiva. De acordo com Clark e Downing (2010), uma grande quantidade de dados somente terá proveito quando possam ser resumidos, logo o papel da estatística descritiva é organizar e sumarizar os dados. Então, buscou-se caracterizar e descrever o conjunto de imóveis de Santa Maria (RS), utilizou-se a média, a mediana, o mínimo, o máximo; bem como, a frequência e o percentual válido em cada faixa percentil de valores.

\section{ANÁLISE DOS RESULTADOS}

A análise foi efetuada sobre os 126.190 cadastros imobiliários ativos que representam os imóveis sobre os quais ocorre a incidência do IPTU no Município de Santa Maria (RS). De acordo com Carvalho Jr. (2017), o cadastro imobiliário é uma ferramenta administrativa complexa, sendo primordial o correto cadastramento dos proprietários e das características físicas dos imóveis, para que a cobrança tenha efetividade.

Em Santa Maria os dados são registrados em uma ficha eletrônica denominada "Boletim Informativo do Cadastro Imobiliário", e esta serve para identificação do contribuinte, localização do imóvel, determinação das características construtivas, entre outros. De acordo com o inciso I do Art. 8o da Lei Complementar Municipal no 02, de 28 de dezembro de 2001 (SANTA MARIA, 2001), a avaliação do terreno considera a forma, a localização do terreno na quadra, a área corrigida e o preço 
do $\mathrm{m}^{2}$ relativo a cada face do quarteirão estabelecido através da planta genérica de valores.

No município a PGV é estabelecida pela Lei Municipal no 3933, de 21 de dezembro de 1995 (SANTA MARIA, 1995), e contem cinco zonas fiscais de localização dos terrenos, e trinta e uma subzonas fiscais que diferenciam os valores do $\mathrm{m}^{2}$ dos terrenos para fins de cálculo do IPTU, bem como definem os percentuais redutores do valor venal relativos ao fator localização. A Tabela 1 apresenta a distribuição dos cadastros nessas zonas e subzonas fiscais, conjuntamente com o preço do $\mathrm{m}^{2}$ do terreno determinado pela PGV.

Tabela 1 - Frequência e percentual válido de cadastros de acordo com a localização na planta genérica de valores, e o valor $\mathrm{m}^{2}$ dos terrenos em cada subzona fiscal.

\begin{tabular}{|c|c|c|c|c|c|c|}
\hline $\begin{array}{l}\text { Zona } \\
\text { fiscal }\end{array}$ & $\begin{array}{c}\text { Frequênci } \\
\text { a } \\
\end{array}$ & $\begin{array}{l}\text { Percentu } \\
\text { al válido }\end{array}$ & $\begin{array}{l}\text { Subzona } \\
\text { fiscal }\end{array}$ & Frequência & \begin{tabular}{|c|} 
Percentual \\
válido \\
\end{tabular} & $\begin{array}{l}\text { Valor do } \mathrm{m}^{2} \\
\text { terreno em } \mathrm{R} \$\end{array}$ \\
\hline \multirow{11}{*}{$1 \underline{a}$} & \multirow{11}{*}{54.053} & \multirow{11}{*}{42,83} & 2 & 3.978 & 3,15 & $1.753,06$ \\
\hline & & & 3 & 1.567 & 1,24 & $1.167,72$ \\
\hline & & & 20 & 9.603 & 7,61 & 973,93 \\
\hline & & & 24 & 117 & 0,09 & 701,22 \\
\hline & & & 25 & 10.849 & 8,60 & 506,44 \\
\hline & & & 26 & 3.128 & 2,48 & 389,55 \\
\hline & & & 27 & 7.461 & 5,91 & 311,63 \\
\hline & & & 28 & 7.937 & 6,29 & 233,69 \\
\hline & & & 29 & 5.494 & 4,35 & 214,24 \\
\hline & & & 30 & 1.972 & 1,56 & 194,78 \\
\hline & & & 31 & 1.947 & 1,54 & 175,23 \\
\hline \multirow{4}{*}{$2^{a}$} & \multirow{4}{*}{6.407} & \multirow{4}{*}{5,08} & 4 & 1.689 & 1,34 & 155,80 \\
\hline & & & 5 & 2.738 & 2,17 & 136,33 \\
\hline & & & 10 & 1.181 & 0,94 & 136,33 \\
\hline & & & 23 & 799 & 0,63 & 116,85 \\
\hline \multirow{5}{*}{$3 \underline{a}$} & \multirow{5}{*}{18.835} & \multirow{5}{*}{14,93} & 6 & 2.741 & 2,17 & 77,86 \\
\hline & & & 7 & 1.028 & 0,81 & 77,86 \\
\hline & & & 8 & 8.978 & 7,11 & 58,44 \\
\hline & & & 9 & 2.821 & 2,24 & 58,44 \\
\hline & & & 21 & 3.267 & 2,59 & 58,44 \\
\hline \multirow{3}{*}{$4 \underline{a}$} & \multirow{3}{*}{19.859} & \multirow{3}{*}{15,74} & 11 & 14.088 & 11,16 & 27,24 \\
\hline & & & 12 & 3.539 & 2,80 & 27,24 \\
\hline & & & 22 & 2.232 & 1,77 & 27,24 \\
\hline \multirow{7}{*}{$5 \underline{a}$} & \multirow{7}{*}{27.036} & \multirow{7}{*}{21,42} & 13 & 3.137 & 2,49 & 27,24 \\
\hline & & & 14 & 10.063 & 7,97 & 27,24 \\
\hline & & & 15 & 2.180 & 1,73 & 27,24 \\
\hline & & & 16 & 3.257 & 2,58 & 27,24 \\
\hline & & & 17 & 6.835 & 5,42 & 11,68 \\
\hline & & & 18 & 1.201 & 0,95 & 11,68 \\
\hline & & & 19 & 363 & 0,29 & 11,68 \\
\hline
\end{tabular}

Fonte: Dados da pesquisa (2018). 
as ruas centrais com prédios de edifícios, o que concentra maior número de imóveis. A 2a Zona Fiscal abrange 5,08\% dos cadastros e compreende bairros no entorno dos bairros mais centrais, enquanto que 3a Zona Fiscal, localiza-se após esta e inclui $14,93 \%$ dos cadastros. É importante salientar que a 4a e 5a Zona Fiscal, cujo percentual é de $15,74 \%$ e $21,42 \%$, abrangem os imóveis localizados nos extremos do centro, representados pelos bairros mais populosos ao leste e oeste da cidade.

Após definir o Valor Venal do Terreno, é necessário quantificar o Valor Venal da Construção. O inciso IV do Art. 8 da LCM no 02/2001 (SANTA MARIA, 2001) determina que a avaliação da construção terá como elementos o preço do $\mathrm{m}^{2}$ estabelecido na PGV de acordo com cada tipo ou características da construção, considerando ainda fatores como a localização, a data da construção, bem como, a área dos imóveis. Estes determinantes são registrados em cada unidade construída.

Com base na área do terreno, na área construída e nos parâmetros estabelecidos na PGV quantifica-se os valores considerados para base de cálculo dos tributos. No Município de Santa Maria o lançamento e a cobrança da Contribuição para Custeio do Serviço de Iluminação Pública ${ }^{1}$ (CIP) das unidades territoriais, bem como da Taxa de Coleta de Lixo $(T C L)^{2}$ são realizadas conjuntamente com o IPTU conforme determina a legislação. A Tabela 2 apresenta a média, mediana, mínimo e máximo dos valores dos imóveis e dos tributos correspondentes.

Tabela 2 - Média, mediana, mínimo e máximo do valor venal do terreno, valor venal da construção, valor venal do imóvel, valor tributável, valor do imposto, valor do imposto com desconto de adimplência, valor da TCL, valor da $\mathrm{CIP}$, valor do tributo, valor da parcela.

\begin{tabular}{l|rrrr}
\hline \multicolumn{1}{c|}{ Variáveis } & \multicolumn{1}{c}{ Média } & Mediana & Mínimo & \multicolumn{1}{c}{ Máximo } \\
\hline Valor venal do terreno & $19.122,14$ & $6.810,00$ & - & $17.898 .772,99$ \\
Valor venal da construção & $74.743,74$ & $49.974,05$ & - & $25.015 .164,28$ \\
Valor venal do imóvel & $93.890,10$ & $61.028,78$ & 167,80 & $37.215 .955,66$ \\
Valor tributável & $35.520,05$ & $15.816,37$ & 40,27 & $22.329 .573,39$ \\
Valor do imposto & 356,13 & 156,64 & 0,40 & $223.295,73$ \\
Valor do imposto com & 331,34 & 145,23 & 0,36 & $200.966,16$ \\
adimplência & & & & \\
Valor da TCL & 80,67 & 54,88 & - & 658,55 \\
Valor da CIP & 73,09 & 76,18 & 19,01 & 133,26 \\
Valor total do tributo & 439,82 & 228,97 & 8,82 & $201.121,11$ \\
Valor da parcela & 38,47 & 20,49 & 8,31 & $14.542,96$ \\
\hline
\end{tabular}

Fonte: Dados da pesquisa (2018).

O valor venal do terreno acrescido ao venal da construção resulta no valor venal dos imóveis, os quais deduzidos dos redutores culminam no valor tributável. Então, pode-se observar que a média do valor venal dos imóveis para fins de cálculo do IPTU é de R\$ 93.890,10, contudo, a média do valor tributável atinge

${ }^{1}$ A Contribuição para Custeio do Serviço de Iluminação Pública é estabelecida na Tabela II da LCM no 74/2009 (SANTA MARIA, Pázíng 9995 .

2 Taxa de Coleta de Lixo é estabelecida na Tabela VI da LCM no 027/2004 (SANTA MARIA, 2004a), que altera o Código Tributário Municipal. 
$37,83 \%$ desse valor, importando em $\mathrm{R} \$ 35.520,05$. Desta comparação, contata-se que os redutores influenciam significativamente no valor utilizado para cálculo do referido imposto. Se for analisada a mediana dessas mesmas variáveis, que representam, respectivamente, $\mathrm{R} \$ 61.028,78$ e $\mathrm{R} \$ 15.816,37$, encontra-se um percentual ainda inferior, pois o valor tributável atinge somente $25,91 \%$ do valor venal.

Do valor tributável resulta um lançamento de IPTU médio de $\mathrm{R} \$ 356,13$ anual por cadastro, o qual tem como mediana um valor de $\mathrm{R} \$ 156,64$. No entanto, se a este valor for efetuado os descontos de adimplência e acrescidos os valores da TCL e CIP, a média sobe para $R \$ 439,82$, e a mediana para $R \$ 228,97$. Essa situação ocorre porque nos boxes, garagens e estacionamentos, a TCL, em média, é $459,93 \%$ superior ao valor do imposto. A divergência entre o valor do imposto e a TCL nos boxes é ocasionada, pois ambos tributos têm bases de cálculo diferentes em função do enquadramento legal.

Além disso, através da estratificação em percentis (10\%) pode-se verificar o número de cadastros em cada faixa de valor, conforme evidenciado na Tabela 3.

Tabela 3 - Valor venal do terreno, valor venal da construção, valor venal do imóvel, valor tributável, valor do imposto, valor do imposto com desconto de adimplência, valor da TCL, valor da CIP, valor do tributo e valor da parcela - em percentis.

\begin{tabular}{|c|c|c|c|c|c|c|c|c|c|c|c|}
\hline \multicolumn{2}{|c|}{ 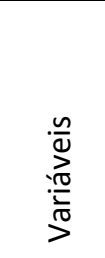 } & 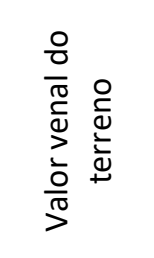 & 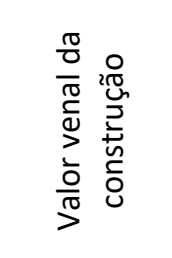 & 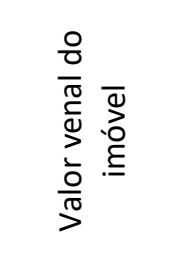 & 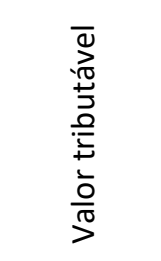 & 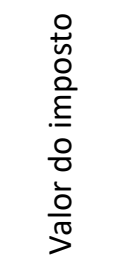 & 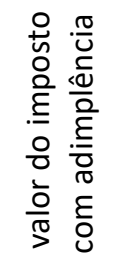 & $\begin{array}{l}\vec{U} \\
\frac{\pi}{0} \\
\frac{\pi}{0} \\
\frac{0}{\pi}\end{array}$ & $\begin{array}{l}\frac{0}{U} \\
\frac{\pi}{0} \\
\frac{1}{\pi} \\
\frac{0}{3}\end{array}$ & 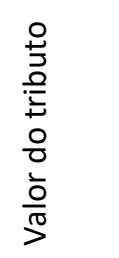 & $\begin{array}{l}\frac{\pi}{0} \\
\frac{0}{0} \\
\frac{2}{0} \\
\frac{0}{0} \\
\frac{0}{0} \\
\frac{0}{\pi} \\
\frac{1}{3}\end{array}$ \\
\hline \multirow{9}{*}{ 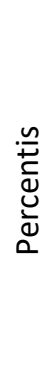 } & 10 & 894,90 & $4.512,36$ & $6.910,50$ & $1.150,75$ & 11,49 & 10,60 & 41,97 & 57,22 & 64,18 & 16,54 \\
\hline & 20 & $1.752,00$ & $7.123,51$ & $11.275,14$ & $2.629,87$ & 40,83 & 37,49 & 41,97 & 57,22 & 96,14 & 16,98 \\
\hline & 30 & $3.103,92$ & $17.722,62$ & $28.860,75$ & $7.988,27$ & 83,57 & 78,93 & 41,97 & 76,18 & 141,36 & 17,47 \\
\hline & 40 & $5.005,12$ & $36.812,00$ & $44.851,25$ & $11.710,82$ & 116,74 & 109,05 & 54,88 & 76,18 & 182,77 & 18,19 \\
\hline & 50 & $6.810,00$ & $49.974,05$ & $61.028,78$ & $15.816,37$ & 156,64 & 145,23 & 54,88 & 76,18 & 228,97 & 20,49 \\
\hline & 60 & $8.931,65$ & $66.825,60$ & $78.955,23$ & $20.147,15$ & 223,77 & 209,76 & 71,02 & 76,18 & 314,24 & 24,73 \\
\hline & 70 & $11.507,49$ & $86.585,52$ & $101.583,46$ & $30.845,34$ & 304,78 & 284,54 & 71,02 & 76,18 & 390,03 & 30,79 \\
\hline & 80 & $18.705,61$ & $112.267,01$ & $132.244,78$ & $40.105,65$ & 401,52 & 376,09 & 83,93 & 76,18 & 499,97 & 39,07 \\
\hline & 90 & $35.596,84$ & $159.946,09$ & $193.159,50$ & $68.282,21$ & 680,55 & 631,25 & 174,32 & 95,24 & 802,08 & 62,71 \\
\hline
\end{tabular}

Fonte: Dados da pesquisa (2018).

Da análise dos percentis, primeiramente verifica-se que o valor tributável representa, em média, somente $26,85 \%$ do valor venal, comprovando o poder dos redutores para redução da base de cálculo do imposto, já diagnosticado através da média e da mediana. Ao mesmo tempo, no primeiro percentil o valor tributável representa $16,65 \%$ do valor venal, enquanto que no nono percentil, representa $35,35 \%$, demonstrando que os redutores diminuem conforme aumenta o valor venal.

Ainda, $50 \%$ dos cadastros tem um valor tributável de até $R \$ 15.816,37$ e assim o valor do imposto correspondente é de até $\mathrm{R} \$ 156,64$ ao ano, o que representa um valor mensal médio de até $R \$ 13,05$. Os $40 \%$ cadastros seguintes tem um valor tributável de até $\mathrm{R} \$ \mathbf{6 8 . 2 8 2 , 2 1}$ e consequentemente um imposto anual de até $R \$ 680,55$, o que representa um valor médio de até $R \$ 56,71$ ao mês. 
A Prefeitura de Santa Maria identificou que os valores venais e tributáveis dos imóveis para fins de IPTU estão abaixo do atual valor de mercado devido a desatualização da planta genérica de valores, pois várias áreas da cidade tiveram valorização pela expansão urbana, instalações de condomínios fechados e obras públicas. Os estudos da nova PGV estão concluídos e aguardam o envio do projeto para análise e aprovação da Câmara de Vereadores.

Corroborando a esta percepção constata-se o desequilíbrio dos valores utilizados como base de cálculo do IPTU pelo município em relação aos preços praticados pelo mercado de imóveis. O portal imobiliário Agente Imóvel Inteligência de Busca (AGENTEIMOVEIS, 2018), apresenta estatísticas e tendências do mercado imobiliário no Brasil, e igualmente para Santa Maria. A Tabela 4 demonstra o preço médio dos imóveis e do $\mathrm{m}^{2}$ de acordo com respectivo site, praticados no mercado em Santa Maria, e o preço do $\mathrm{m}^{2}$ do valor venal e tributável dos imóveis de acordo com os dados da prefeitura. Destaca-se que o valor do $\mathrm{m}^{2}$ para esta, refere-se a um valor estimado, pois foi obtido através da divisão do valor venal e valor tributável dos respectivos cadastros pela área construída, desconsiderando-se a metragem do terreno ou a fração ideal deste.

Tabela 4 - Preço do imóvel e do $\mathrm{m}^{2}$ no mercado - em R\$̦, preço estimado do $\mathrm{m}^{2}$ do valor venal e tributável para a Prefeitura Municipal de Santa Maria - em $\mathrm{R}$; variação percentual entre ambos, por bairros e cidade.

\begin{tabular}{l|l|rr|rr|rr}
\hline \multirow{2}{*}{\multicolumn{2}{c|}{ Variáveis }} & \multicolumn{2}{|c|}{ Agente Imóveis - R\$ } & \multicolumn{2}{c|}{ Prefeitura - R\$ } & \multicolumn{2}{c}{ Variação (\%) } \\
\cline { 3 - 7 } \multicolumn{1}{c|}{} & $\begin{array}{c}\text { Preço médio } \\
\text { imóvel }\end{array}$ & $\begin{array}{c}\text { Preço } \\
\text { médio } \mathrm{m}^{2}\end{array}$ & $\begin{array}{c}\text { Preço } \mathrm{m}^{2} \\
\text { venal }\end{array}$ & $\begin{array}{c}\text { Preço } \mathrm{m}^{2} \\
\text { tributável }\end{array}$ & $\begin{array}{c}\text { Do valor } \\
\text { venal }\end{array}$ & $\begin{array}{c}\text { Do valor } \\
\text { tributável }\end{array}$ \\
\hline \multirow{6}{*}{ Bairros } & Na Sa da Dores & $580.577,00$ & $4.438,00$ & 868,83 & 251,65 & 510,80 & $1.763,58$ \\
& Na Sa de Lourdes & $540.170,00$ & $4.764,00$ & 925,91 & 280,88 & 514,52 & $1.696,11$ \\
& Menino Jesus & $485.982,00$ & $4.513,00$ & 757,78 & 202,96 & 595,55 & $2.223,63$ \\
& São José & $480.367,00$ & $3.376,00$ & 959,59 & 319,45 & 351,82 & $1.056,82$ \\
& Nonoai & $432.760,00$ & $4.385,00$ & 870,00 & 249,79 & 504,02 & $1.755,44$ \\
& Na Sa de Fátima & $428.206,00$ & $4.273,00$ & 918,66 & 278,54 & 465,14 & $1.534,08$ \\
& Centro & $425.863,00$ & $4.336,00$ & $1.003,56$ & 297,15 & 432,06 & $1.459,21$ \\
& Camobi & $406.067,00$ & $4.294,00$ & 775,81 & 229,38 & 553,48 & $1.871,99$ \\
& Na Sa Medianeira & $384.307,00$ & $3.958,00$ & 885,46 & 262,46 & 447,00 & $1.508,01$ \\
& Pinheiro Machado & $329.211,00$ & $3.222,00$ & 790,90 & 220,65 & 407,39 & $1.460,25$ \\
& Na Sa do Rosário & $313.794,00$ & $4.353,00$ & 964,10 & 272,07 & 451,51 & $1.599,98$ \\
& Uglione & $304.368,00$ & $4.265,00$ & 822,07 & 256,36 & 518,81 & $1.663,67$ \\
\hline \multirow{2}{*}{ Cidade } & Média & $415.151,00$ & $4.149,00$ & 899,43 & 263,34 & 461,29 & $1.575,53$ \\
& Mediana & $320.000,00$ & $4.058,00$ & 839,17 & 224,67 & 483,57 & $1.806,20$ \\
\hline
\end{tabular}

Fonte: Agente Imóveis (Semana de 30/04/2018) e dados da pesquisa (2018).

Verifica-se que em todos os bairros, de acordo com o site Agente Imóveis Inteligência de Busca (AGENTEIMOVEIS, 2018), o valor do $\mathrm{m}^{2}$ do mercado supera o valor do $\mathrm{m}^{2}$ dos valores venais e tributáveis. As diferenças são expressivas em todos os locais da cidade, apresentando variação entre $351,82 \%$ até $595,55 \%$ quando comparado ao valor venal, e de $1.056,82 \%$ até $2.223,63 \%$ quando comparado ao valor tributável.

$\mathrm{Na}$ análise por bairros a maior diferença é encontrada nos bairros Menino Jesus e Camobi; a menor é encontrada nos bairros São José e Pinheiro Machado. Destaca-se que é explícita a valorização dos imóveis nos bairros que se localizam nas extremidades da cidade nos últimos anos, porém, nestes, a maioria dos imóveis pela planta genérica de valores encontram-se situados na $4 \underline{a}$ e $5 \underline{a}$ Zona 
Fiscal, onde o preço do $\mathrm{m}^{2}$ do terreno, que varia de $R \$ 11,68$ até $R \$ 27,24$, é o mais baixo.

Em relação a cidade, a variação média apresentada é de $461,29 \%$ para o valor venal, aumentando para $1.575,53 \%$ quando considerado o valor tributável. Para as medianas a variação é ainda maior, representando 483,57\% para o valor venal, e $1.806,20 \%$ quando comparado ao valor tributável. Portanto, a desatualização tanto do valor venal, quanto do valor tributável é perceptível em toda cidade, necessitando de uma revisão dos valores que compõem a base de cálculo do IPTU, bem como nos redutores que incidem sobre esta.

Deste modo, destaca-se que a falta de reavaliações recorrentes, devido a avaliações defasadas, torna o imposto imobiliário altamente questionável, pois os valores de mercado podem desvalorizar-se ou valorizar-se consideravelmente a médio e longo prazo. Assim, é fundamental que exista algum mecanismo legal, por lei federal, tornado obrigatória a atualização periódica da planta genérica de valores, de quatro em quatro anos, e ainda sejam definidas limitações para as isenções ou reduções da base de cálculo (CARVALHO JR., 2017).

\section{CONSIDERAÇÕES FINAIS}

Aos municípios cabe buscar todos os recursos que lhe pertencem por direito, de acordo com a matriz tributária, para que possam realizar atividades para a melhoria da qualidade de vida dos seus cidadãos conforme é preconizado constitucionalmente. No Município de Santa Maria (RS), dentre os três impostos de sua competência, o Imposto Sobre Propriedade Predial e Territorial Urbana IPTU destaca-se pelo baixo nível de arrecadação em vista do número de imóveis, influenciado, em parte, pela defasagem da planta genérica de valores.

Evidencia-se que somente com o amplo conhecimento dos aspectos que compõem um problema, este poderá ser amenizado. Diante desse contexto, o estudo teve como objetivo constatar os índices da defasagem da PGV no Município de Santa Maria (RS).

Destaca-se que no município ocorreu uma valorização imobiliária, com a construção de imóveis de alto padrão, em vários locais e especialmente nos extremos da cidade, cujas zonas fiscais correspondem aos menores preços dos terrenos pela planta genérica de valores. Por isso, salienta-se que o ideal é a implantação de uma nova PGV, a qual estipule uma metodologia de cálculo que contemple as variações dos preços dos imóveis ocorridas no município, de forma que o tributo seja mais igualitário em todas as regiões valorizadas, promovendo a tão esperada justiça fiscal, e o aumento da arrecadação. Contudo, deve-se advertir que a aprovação da mesma depende da compreensão do legislativo municipal, o qual apresenta, muitas vezes, dificuldades em matérias técnicas, especialmente as tributárias, por terem grande impacto no eleitorado.

Nesse quesito, de acordo com o que acontece em outros impostos, principalmente o ISS, deveria haver algum mecanismo legal que determinasse os parâmetros de cálculo, estipulando, ainda, limitações para as isenções e os redutores, propiciando aos municípios apenas a adequação destes a sua realidade local. Na falta desses, ao menos a obrigatoriedade de atualização da planta genérica de valores. Entende-se, pela prática, que a mesma deveria ser atualizada no mínimo de cinco em cinco anos. 
Como maior contribuição do estudo, do ponto de vista municipal, destacase que a abordagem diagnosticou estatisticamente a defasagem da PGV podendo servir de instrumento de convencimento para a necessidade de atualização da mesma, uma vez que, o estudo está pronto, dependendo do envio e aprovação para a Câmara Municipal de Vereadores. Para a academia, as principais contribuições dizem respeito à ampliação do conhecimento em relação a área pública, aprofundando os aspectos da tributação do Imposto Predial e Territorial Urbano - IPTU. Do ponto de vista da sociedade, além de promover justiça fiscal, pode promover melhores serviços, investimentos para o bem comum e políticas públicas de relevante interesse social, proporcionados pelos recursos arrecadados.

Portanto, entende-se como fundamental a revisão da planta genérica de valores, para que a arrecadação municipal dos tributos seja realizada em sua plenitude, atingindo os níveis totais legalmente estabelecidos, em conformidade com a Lei de Responsabilidade Fiscal. Como limitações, descreve-se as inconsistências de alguns dados do cadastro imobiliário e os escassos estudos a nível municipal e a diminuta bibliografia a respeito do IPTU. Como sugestões para estudos futuros, recomenda-se a realização de pesquisa no município, efetuandose um comparativo dos valores da atual planta genérica de valores, com a proposta ora elaborado pelo município, ainda pendente de aprovação, para avaliar os impactos e a contribuição da mesma. 


\title{
The problem of the generical plant of values in the IPTU of a gaúcho municipal
}

\begin{abstract}
The municipalities must promote the collection of taxes of their competence to carry out their multiple activities for the common good of citizens. In the Municipality of Santa Maria (RS), the Property and Urban Property Tax (IPTU) stands out due to the low level of collection, influenced in part by the lack of a generic values plant (PGV). The study aimed to verify and identify the percentage of the generic values plant gap. Then, a descriptive research, with quantitative approach and descriptive statistical techniques was used. It sampled the data and financial data of 126,190 real estate registered in the real estate sector. Based on the descriptive statistics, it verified that the appraised and taxable values are below the market value, due to the application of reducers and lag of the generic plant of values. The estimated imbalance between the values practiced by the market and by the Municipality through the PGV, presents an average lag of $461.29 \%$ and $1.575 .53 \%$, respectively, for the appraised and taxable values of real estate. The devaluation of both is noticeable in every city, demonstrating the need for a revision of the values that make up the calculation basis of the IPTU.
\end{abstract}

KEYWORDS: Municipality, Revenue, IPTU, Generic Plant of Values. 


\section{REFERÊNCIAS}

AFONSO, J. R. R.; ARAÚJO, E. A.; NÓBREGA, M. A. R. IPTU no Brasil: Um Diagnóstico Abrangente. Brasília/DF e Rio de Janeiro/RJ: Instituto Brasiliense de Direito Público IDP Ltda e FGV Projeto, v. 4, 2013.

AGÊNCIA DE DESENVOLVIMENTO DE SANTA MARIA. Habitação. Santa Maria, 2017. Disponível em: <http://santamariaemdados.com.br/8-infraestrutura/9-2habitacao/>. Acesso em: 22 maio 2017.

AGENTE IMÓVEL INTELIGÊNCIA DE BUSCA. Tendências. Preço dos Imóveis em Santa Maria. Abril 2018. Disponível em: < https://www.agenteimovel.com.br/mercado-imobiliario/a-venda/urlandia,santamaria,rs/preco_medio_m2/>. Acesso em: 28 maio 2018.

AMARO, L. Direito Tributário Brasileiro. 21. ed. São Paulo: Saraiva, 2016.

BRASIL. Constituição da República Federativa de 1988. Disponível em: <http://www.planalto.gov.br/ccivil_03/Constituicao/ConstituicaoCompilado.htm >. Acesso em: 17 out. 2017.

Lei $n^{\circ} 5.172$, de 25 de outubro de 1966. Dispõe sobre o Sistema Tributário Nacional e institui Normas Gerais de Direito Tributário aplicáveis a União, Estados e Municípios. Disponível em: <http://www.planalto.gov.br/ccivil_03/leis/15172.htm>. Acesso em: 15 maio 2016.

Lei Complementar $n^{\circ} 101$, de 04 de maio de 2000. Estabelece normas de finanças públicas voltadas para a responsabilidade na gestão fiscal e dá outras providências. Disponível em:

<http://www.planalto.gov.br/ccivil_03/leis/lcp/lcp101.htm >. Acesso em: 15 maio 2016.

Lei Complementar $n^{\circ} 116$, de 31 de julho de 2003. Dispõe sobre o Imposto Sobre Serviços de Qualquer Natureza, de competência dos Municípios e do Distrito Federal, e dá outras providências. Disponível em:

<http://www.planalto.gov.br/ccivil_03/leis/LCP/Lcp116.htm >. Acesso em: 15 maio 2016.

Lei Complementar $n^{\circ} 123$, de 14 de dezembro de 2006. Institui o Estatuto Nacional da Microempresa e da Empresa de Pequeno Porte; altera dispositivos das Leis no 8.212 e 8.213, ambas de 24 de julho de 1991, da Consolidação das Leis do Trabalho - CLT, aprovada pelo Decreto-Lei no 5.452, de 10 de maio de 1943, da Lei no 10.189, de 14 de fevereiro de 2001, da Lei 
Complementar no 63, de 11 de janeiro de 1990; e revoga as Leis no 9.317, de 5 de dezembro de 1996, e 9.841, de 5 de outubro de 1999. Disponível em: <http://www.planalto.gov.br/CCivil_03/leis/LCP/Lcp123.htm>. Acesso: 05 mar. 2018.

Lei Complementar $n^{\circ} 12.527$, de 18 de novembro de 2011. Regula o acesso a informações previsto no inciso XXXIII do Art. 5o, no inciso II do $\S 30$ do Art. 37 e no § 20 do Art. 216 da Constituição Federal; altera a Lei no 8.112, de 11 de dezembro de 1990; revoga a Lei no 11.111, de 5 de maio de 2005, e dispositivos da Lei no 8.159, de 8 de janeiro de 1991; e dá outras providências. Disponível em: < http://www.planalto.gov.br/ccivil_03/_ato20112014/2011/lei/l12527.htm>. Acesso em: 07 out. 2017.

CARVALHO JR., P. H. B. O sistema avaliatório municipal de imóveis e a tributação do IPTU no Rio de Janeiro. 2011. 101 p. Dissertação (Mestrado em Ciências Econômicas - Políticas Públicas) - Universidade do Estado do Rio de Janeiro UERJ, Rio de Janeiro, 2011.

CARVALHO JR., P. H. B. Imposto Predial e Territorial Urbano - IPTU. Plataforma de Política Social. ANFIP. Reforma Tributária. n. 05, 2017.

CHIMENTI, R. C; PIERRI, A. T. Teoria e prática do direito tributário. 3. ed. rev. e atual. de acordo com as Leis Complementares n. 139/2011 e 141/2012. São Paulo: Saraiva, 2012.

CLARK, J.; DOWNING, D. Estatística Aplicada - Série Essencial. 3ae ed. São Paulo: Saraiva, 2010.

CUPERTINO, S. A. Avaliação da arrecadação do Imposto Sobre Propriedade Predial e Territorial Urbana no Município de Viçosa - MG. 2013.87 p. Dissertação (Mestrado em Administração) - Universidade Federal de Viçosa, Viçosa, 2013.

DEEPASK. O Mundo e as Cidades através de Gráficos e Mapas. Finanças Públicas. IPTU: Veja arrecadação de imposto sobre propriedade urbana por cidade do Brasil. Brasil, 2017. Disponível em:

<http://www.deepask.com/goes?page=Imposto---IPTU:-Veja-a-receita-tributariano-seu-municipio>. Acesso em: 26 out. 2017.

DIÁRIO DE SANTA MARIA. Imposto. Prefeitura de Santa Maria quer cobrar IPTU de todos os puxadinhos e imóveis irregulares a partir de 2018. Santa Maria, 2017a. Disponível em: <http://diariodesantamaria.clicrbs.com.br/rs/economiapolitica/noticia/2017/01/prefeitura-de-santa-maria-quer-cobrar-iptu-de-todosos-puxadinhos-e-imoveis-irregulares-a-partir-de-2018-9590746.html>. Acesso em: 21 out. 2017. 
Planta de Valores não será atualizada, e IPTU só deve subir a partir de 2019. Santa Maria, 2017b. Disponível em:

<http://diariosm.com.br/not\%C3\%ADcias/economia/iptu-s\%C3\%B3-deve-subir-apartir-de-2019-em-santa-maria-1.2033970>. Acesso em: 08 mar. 2018.

FIRJAN. Índices Firjan. Índice Firjan De Gestão Fiscal. Ano Base 2016.Recorte Municipal Abrangência Nacional. Ago. 2017. Disponível em:

$<$ http://www.firjan.com.br/data/files/

4A/B0/A3/B1/C4CCD51063C6AAD5A8A809C2/IFGF\%202017\%20-

\%20An_lise\%20Especial\%20-\%20Vers_o\%20Completa.pdf>. Acesso em: 12 out. 2017.

LAKATOS, E. M.; MARCONI, M. A. Metodologia do Trabalho Científico. 8. ed. São Paulo: Atlas, 2017.

MATIAS-PEREIRA, J. Manual de Metodologia da Pesquisa Científica. 4.ed. São Paulo: Atlas, 2016.

MICHEL, H. M. Metodologia e Pesquisa Científica em Ciências Sociais: um guia prático para acompanhamento da disciplina e elaboração de trabalhos monográficos. 3a ed. São Paulo: Atlas, 2015.

OLIVEIRA JR., L. A. Potencial de Arrecadação do IPTU: análise nacional do Município de Santa André. 2014. 126 p. Dissertação (Mestrado Profissional em Gestão e Políticas Públicas) - Fundação Getúlio Vargas, São Paulo, 2014.

SÁ, J. D.; CAVALCANTE, C. A. M. T.; KALID, R. A.; MALVEIRA, U. A. Um modelo de otimização para alíquotas do IPTU socialmente mais justas. Revista de Administração Pública - RAP, Rio de Janeiro, v. 47, n. 1, p. 105-132, jan-fev, 2013.

SANTA MARIA. Lei Complementar Municipal n 02, de 28 de dezembro de 2001. Estabelece, altera e consolida o Código Tributário do Município, consolidando a Legislação Tributária e dá outras providências.

Lei Complementar Municipal no 27, de 30 de setembro de 2004a. Altera a Lei Complementar no 02, de 28 de dezembro de 2001. Disponível em: <http://www.camara-sm.rs.gov.br/camara/proposicao/LeiComplementar/2004/1/0/9165\#lista_texto_proposicao>. Acesso em: 26 maio 2018. 
Lei Complementar Municipal no 28, de 15 de dezembro de 2004b. Altera a Lei Complementar no 02/2001, de 28-12-2001 - Código Tributário do Município e dá outras providências. Disponível em: <http://www.camarasm.rs.gov.br/camara/proposicao/LeiComplementar/2004/1/0/9164\#lista_texto_proposicao>. Acesso em: 26 maio 2018.

Lei Complementar Municipal no 76, de 30 de setembro 2009a. Altera as Leis Complementares no 028/04, de 15 de dezembro de 2004, e no 027/04, de 30 de setembro de 2004, que modificam o Código Tributário do Município. Disponível em: <http://www.camara-sm.rs.gov.br/camara/proposicao/LeiComplementar/2009/1/0/9117\#lista_texto_proposicao>. Acesso em: 19 jun. 2018.

Lei Complementar Municipal no 74, de 30 de dezembro de 2009c. Institui no Município de Santa Maria a Contribuição para Custeio do Serviço de Iluminação Pública Prevista no Artigo 149-A da Constituição Federal. Disponível em: < http://www.camara-sm.rs.gov.br/camara/proposicao/LeiComplementar/2009/1/0/9119\#lista_texto_proposicao>. Acesso em: 20 jun. 2018.

Lei Municipal no 3933, de 21 de dezembro de 1995. Fixa valores de Taxas, Planta de Valores, Redutores e Prazos de Impostos Municipais.

Decreto Executivo Municipal no 145, de 04 de dezembro de 2008. Regulamenta o Imposto Predial e Territorial Urbano do Município de Santa Maria- IPTU.

Decreto Executivo Municipal no 159, de 19 de novembro de 2017. Dispõe sobre o Cálculo e Arrecadação dos Tributos Municipais para o Exercício de 2018.

SOARES, C. S.; FLORES, S. A. F.; CORONEL, D. A. O Comportamento da Receita Pública Municipal: Um Estudo de Caso no Município de Santa Maria (RS). Desenvolvimento em Questão, ljuí (RS), v. 12, n. 25, pp. 312-338, jan-mar., 2014. 
Recebido: 28 out. 2019

Aprovado: 03 dez. 2019.

DOI: $10.3895 /$ rbpd.v9n1.9696

Como citar: GERING, S. M. P.; PINTO, N. G. M.; VIEIRA, K. M. A problemática da planta genérica de

valores no IPTU de um município gaúcho. R. bras. Planej. Desenv. Curitiba, v. 9, n. 1, p. 126-145, jan./abr.

2020. Disponível em: <https://periodicos.utfpr.edu.br/rbpd>. Acesso em: XXX.

Correspondência:

Nelson Guilherme Machado Pinto

Av. Roraima, 1000 - Cidade Universitária - Camobi - Santa Maria, RS

Direito autoral: Este artigo está licenciado sob os termos da Licença CreativeCommons-Atribuição 4.0

Internacional.

(c) (1) 